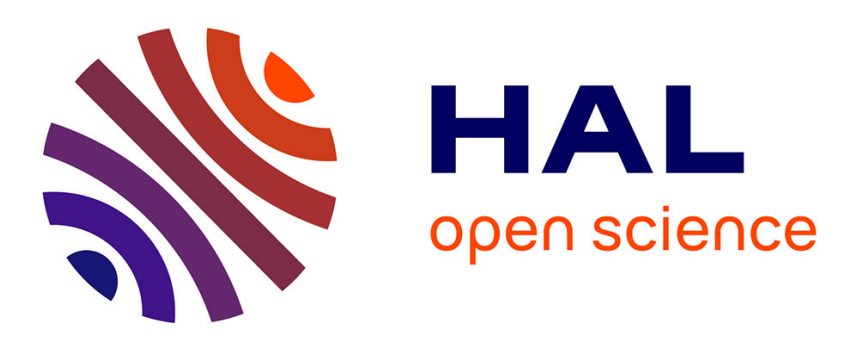

\title{
Usability of Knowledge Portals for Exclusives in Local Governments
}

\author{
Krzysztof Hauke, Mieczyslaw L. Owoc, Maciej Pondel
}

\section{To cite this version:}

Krzysztof Hauke, Mieczyslaw L. Owoc, Maciej Pondel. Usability of Knowledge Portals for Exclusives in Local Governments. 2nd IFIP International Workshop on Artificial Intelligence for Knowledge Management (AI4KM), Sep 2014, Warsaw, Poland. pp.92-106, 10.1007/978-3-319-28868-0_6 . hal01369803

\section{HAL Id: hal-01369803 \\ https://hal.inria.fr/hal-01369803}

Submitted on 21 Sep 2016

HAL is a multi-disciplinary open access archive for the deposit and dissemination of scientific research documents, whether they are published or not. The documents may come from teaching and research institutions in France or abroad, or from public or private research centers.
L'archive ouverte pluridisciplinaire HAL, est destinée au dépôt et à la diffusion de documents scientifiques de niveau recherche, publiés ou non, émanant des établissements d'enseignement et de recherche français ou étrangers, des laboratoires publics ou privés. 


\title{
Usability of Knowledge Portals for exclusives in local governments
}

\author{
Krzysztof Hauke \\ Wroclaw University of Economics \\ Komandorska 118/120, \\ 53-345 Wrocław, Poland \\ Email: krzysztof.hauke@ue.wroc.pl
}

\author{
Mieczysław L. Owoc \\ Wroclaw University of Economics \\ Komandorska 118/120, \\ 53-345 Wrocław, Poland \\ Email: mieczyslaw.owoc@ue.wroc.pl
}

\author{
Maciej Pondel \\ Wroclaw University of Economics \\ Komandorska 118/120, \\ 53-345 Wrocław, Poland \\ Email: maciej.pondel@ue.wroc.pl
}

\begin{abstract}
Exclusion phenomenon in common understanding denotes processes in which members of society or groups of people are permanently blocked from resources (mostly considered as social exclusion). No doubts, such sort of phenomena is observed as unwanted not only from "outsiders" but also from local and global society points of view. The exclusion (and its antonym inclusion) phenomenon can be investigated including many perspectives: starting from identifying exclusion as a process, through multidimensional aspects up to solutions available in the domain. In order to be successful in overtaking this phenomenon groups and institutions involved in this process should be supported by ICT solutions. The paper consists of six parts which gradually present context of the problem and proposed solutions. After short introduction concerning research background the discussed concept of exclusion processes and knowledge portals are presented. In the main section a general idea of knowledge portal for exclusives is proposed and specialty of these portal for regional implementation in the Silesia agglomeration is discussed. It creates opportunities for formulation final conclusions about the necessity and usability of the developed platform.
\end{abstract}

\section{INTRODUCTION}

People living in the era of information society, know more and more about a man, groups and the whole nations, about their needs and levels of satisfaction of the human beings alone or of human associations. If so, natural tendency present in democracy - to treat all citizens equally becomes very important. Any form of discrimination of some group of people is against the democratic order and societies and governments try to counteract with this unwanted phenomenon.

The roots of the exclusion phenomena "discovering" (or better reflexion on human sense of equality and justice) can be found in the discourse in France in the mid 1970s (see: N. Rawal review of social inclusion and exclusion - [11]). A bit later H. Silver (see: [1]) formulated three paradigms of social exclusion: solidarity (stressing social dimension of human interactions), specialization (discovering exclusion as a form of discrimination) and monopoly (interpreting exclusion as a consequence of the existing group monopolies). Anyway in older and later approaches to the phenomena research many aspects of social exclusion and inclusion were analysed.

In order to be successful, a problem of exclusion should be investigated, reasons of its occurrence should be discovered and solutions for inclusion should be proposed. According to European Union policies the poverty and exclusion 
problems are very important and responses could be projects prepared in the Europe 2020 strategy (Societal challenges section in Horizon 2020 programme, see: [14]).

Two examples should be stressed as promising solutions in the discussed area:

- GSDRC - Applied Knowledge Services devoted to maintaining knowledge about exclusion phenomena (see: [12])

- Exclusion-Inclusion Suburbs - prepared for knowledge services essential in city environments (see: [13]).

In both cases presented solutions are limited to selected phases or areas of exclusion phenomena. Therefore lack of common platform developed for the whole community seems to be obvious.

The paper is managed as follows. In the next section theoretical background of the investigated phenomena is described including nature of exclusion and inclusion phenomena, reasons of its occurrence is discussed and multidimensional characteristics of investigation is stressed. An essence of knowledge portals developed for modern society is presented in the subsequent section with focus on society needs and functionality of such portals, offered architectures and applications useful for different segments of the society. The most innovative part of the research is presented in the main section of the paper devoted to concepts of the knowledge portal addressed to exclusives covering: assumptions, architecture and examples of supported tasks. Implementation aspects essential for local governments in one of Polish agglomeration are discussed in the next section. The paper ends with conclusion remarks and future research.

\section{EXCLUSION PROCESSES AS RESEARCH CHALLENGES}

No doubts, exclusion as a phenomenon seems to be very important and difficult problems to solve in modern society. There are many contexts in which exclusionary processes can occur including different objects, or time- and territory- aspects. At least two approaches should be taken into account actorsoriented and capability-oriented.

In accordance to the first one the critical thing is: relationships between entities (e.g. "actors") essential for the exclusion. It is very important in understanding the "exclusion" idea as a concept. According to R Saith: [2] "Social exclusion is a socially constructed concept, and can depend on an idea of what is considered "normal"'. So here the crucial topic of understanding of the discussed phenomenon is a definition of normality which, in turn, depends on standard living, hierarchy of values, assumed criteria of society organization and the like what finally can be identified with "actors".

On the other hand A.Sen (see: [3]) keeps that an essence of social exclusion relates to 'functionings' and 'capabilities' concepts. Functionings denotes things important in leading life (health, education, cultural life etc.) while capabilities concerns individual combination of different functionings specific for humanbeings or some group of people. So, social exclusion relies on inability of achieving certain 'functionings' or difficulties with reaching the goals which leads to deprivation and poverty - unwanted states in any society. 
Multi-dimensional character of exclusion has been stressed by the following authors: De Haan [4], Bhalla and Lapeyre [6], Burchardt et. al. [5] and Fisher [7]. Potential dimensions cover the different aspects: un/employment, markets (so difficulties with access to goods and services), neglecting of political laws and social relationships. Therefore in research conducted in this domain all aspects of exclusion processes should be examined not only individually but also from more general point of view. There are many intersections between the mentioned dimensions, for example: unemployment has the strong impact on poverty, poverty in turn causes limited access to services and products available on a market in local and global range and so on.

From individual as well as from society points of view the mentioned manifestations of exclusion processes lead to segregation of many sorts, sense of social inequality and conflicts in broader perspectives. Monitoring and investigation of the discussed phenomenon need to be performed continuously and be supported by information and communication technologies or better by specialized knowledge portals.

The described phenomenon basically relates to social exclusion which should be separated from voluntary exclusion - see Barry [8]. Exclusion of this sort is a specific one and not always is regarded as an unwanted process. On the contrary, as intentionally prepared and performed activities cannot be integrated with social exclusion.

The process considered as the solution to neutralize exclusion effects is called social inclusion. The social inclusion can be defined as ...” process of improving the terms on which people take part in society" - see World Bank definition [15]. In sociology social inclusion means the provision of certain rights to all individuals and groups in society, such as employment, adequate housing, health care, education and training, etc. - see Collins Dictionary [12]. Of course social inclusion - as the process of organizing social life - sometimes is problematic or even inequitable - see Hickey and du Toit [9]. The concept of 'adverse corporation' brings better results because of its implementation in particular contexts - see [9].

Social inclusion as the process of counteraction of negative results of exclusion should be supported in many ways by information technologies. Social equality should be enforced by access to information and knowledge available in computer networks; M. Warschauer discussed many aspects of usability and consequences of technology and social inclusion intersection see [10]. In the next part importance of knowledge portals as natural source of information for modern society is presented.

\section{KNOWLEDGE PORTAL FOR THE MODERN SOCIETY}

Let us start discussion about portals from original definition of this term. The name - portal - comes from the portal architecture and denotes a door frame in the palaces, churches, town halls, etc. Portals were so meant to be gateways to the Internet, to the wide world for each user.

Portal - a website presenting the overview and systematic form the most important and best - developed articles, as well as other content related to the 
topic. It presents readers with the resources available on the subject in a more accessible and attractive than categories, indirectly encouraging the active involvement in the development of the content.

Portal - the website term, usually is seen as larger and more extensive than normal information or hobby pages. Internet portal, in addition to the information function, has various facilities for the user, such as: to customize the appearance of the page, the search engine websites also offer additional services, such as emailing or downloading files. Most portals encourages users to exchange opinion and discussion, allowing them to comment on articles published on them.

Web Portal (or Internet portal) - an online news service expanded to include a variety of features available, accessible from a single web address. The intention of the portal creators is to encourage users to set the address as the portal home page in a Web browser, and treat it as a gateway to the Internet.

Typically, the portal contains information of interest to a wide audience. As an example, you can specify the content of the website: sections of portals refer to current news, weather, websites, chat, discussion forum and information retrieval mechanisms.

Therefore we may call Web Portal - as an online information services extended to a variety of Internet functions, available from a single Internet address (compare [17]). Typically, the portal contains information of interest to a wide audience. In addition, web portals may offer free services such as email, web hosting.

Going further - Corporate Portal - can be defined as an integrated user interface, developing websites, and for the exchange of information, knowledge management in the company and the implementation of various business transactions. This is a point of access to all information resources and applications used. It integrates systems and technology, data, information and knowledge to function in the organization and its environment, in order to allow users a personalized and convenient access to data, information, knowledge, according to the tasks arising from their needs, anywhere, anytime, in safe manner and through a single interface. More advanced portals act as powerful workplace to ensure collaboration and exchange of documents. Fig. 1 [24]

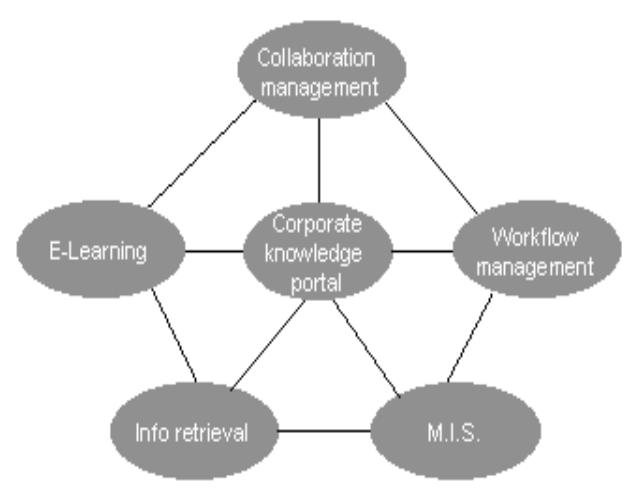

Fig. 1. Elements of Corporate Portals 
C. Shilakes and J. Tylmann from Merill Lynch are recognized as creators of the Corporate Portals (CP) concept [21]. These portals should represent the following features [22]:

- integration of heterogeneous data, structured and unstructured, from the organization and its environment,

- integration of heterogeneous applications,

- providing information onto users, both automatically to authorized users and each of their request,

- $\quad$ portal interface can be adapted to individual needs,

- providing in-depth information and knowledge on very specific areas of individual users and groups of users,

- creating opportunities for communication, information sharing and collaboration between users or groups of users,

- categorizing data, information and knowledge available through the portal,

- publication and distribution of information and knowledge and its dissemination among employees.

The overall architecture of CP embraces four layers:

- presentation layer and personalization: defines how each user access to resources and services of the portal,

- taxonomy and search layer conditioning the ease and speed of getting the information sought,

- $\quad$ security layer: a very important element of the architecture. Portal must have built-in controls that effectively secure the data, knowledge, information, and applications from unauthorized access,

- integration layer: provides access to the data existing in the organization and its environment. Portal integrates applications and resources to facilitate access to them.

As a result we may formulate the following benefits of corporate portals:

- $\quad$ quick access to key information necessary for decision-making,

- $\quad$ reduce the time searching for the necessary information,

- $\quad$ access to knowledge regardless of the location of users,

- good organization of work thanks to the integrated access to information.

- reduce the cost of distribution of information, mainly a reduction in spending on calls and paper.

More advanced version of CP is Knowledge Portal. "Knowledge Portal as a type of portal that purposely supports and stimulates knowledge transfer, knowledge storage and retrieval, knowledge creation, knowledge integration, and knowledge application (i.e., the processes of knowledge management) by providing access to relevant knowledge artifacts. Repository-oriented components and functionalities of a knowledge portal include a knowledge organization system, repository access, search, and applications and services. In addition to the repository-oriented functionality of a knowledge portal, such a portal must also offer network-oriented components and functionalities. Some types of knowledge are most readily transferred through direct interaction between a knowledge seeker 
and another knowledgeable individual. To that end, a knowledge portal also provides functionalities to identify and connect users based on their expertise, such as collaboration and communication tools" [25].

Knowledge Portal (KP) - can be defined as an online service that includes a generally reliable information about a specific fragment of reality and can be used in the further development of the issues or bind it with another issue. Knowledge expressed in many forms including its own theories is a crucial component of the discussed portals. The classic approach takes into account the following elements of KP:

- beliefs - judgments in the logical sense,

- justification - the belief is justified,

- veracity - the belief is true.

Typical examples of knowledge portal categories are:

- social sciences and humanities, such as astronomy, biology, chemistry, genetics, medical science, zoology,

- society, such as: anarchism, atheism, bible, biographies, philately, Hinduism, Judaism, Catholicism, the saints, the religious,

- geography, for example: individual continents, different countries, selected cities,

- national, for example, Poland, Germany, USA,

- culture - fiction, film, comics, art, games, anime,

- sports, for example, the Olympic Games, check, ski jumping, rallies,

- technique, such as: architecture, electronics, energy, computers, mobile phones, websites, army,

- social sciences and humanities, such as philosophy, history, psychology, sociology, foreign languages,

One of the oldest knowledge portals is presented in Fig. 2 (see: [19]). Main functionality of the portal concerns to co-operation with experts, e-learning offerings, Case Law Directory apart of typical FAQ (frequently asked questions) capabilities.

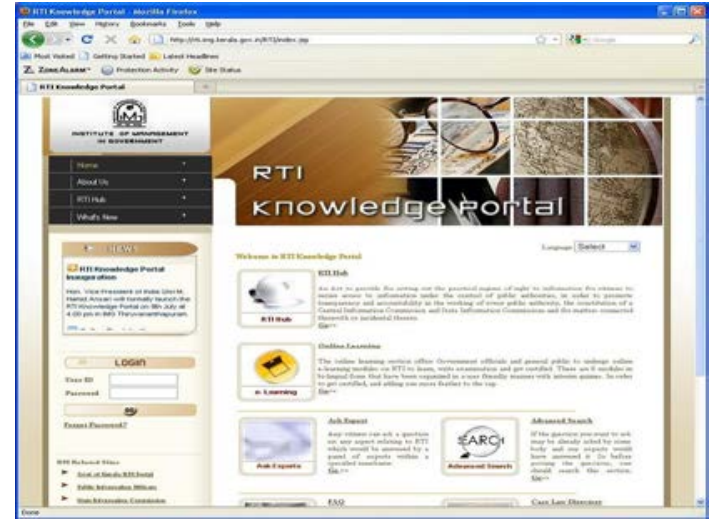

Fig. 2. An example of RTI Knowledge Portal 
Next presented KP is ICSI Knowledge Portal (ICSI-KP) “a capacity building initiative of the Institute of Company Secretaries of India (ICSI) for its members and students is a reservoir of knowledge enabling the users access to huge pool of information including Bare Acts, case laws, notifications and circulars issued by Government and regulatory authorities from time to time" - description available from eJurix on the ICSI KP home page Fig. 3 [23].

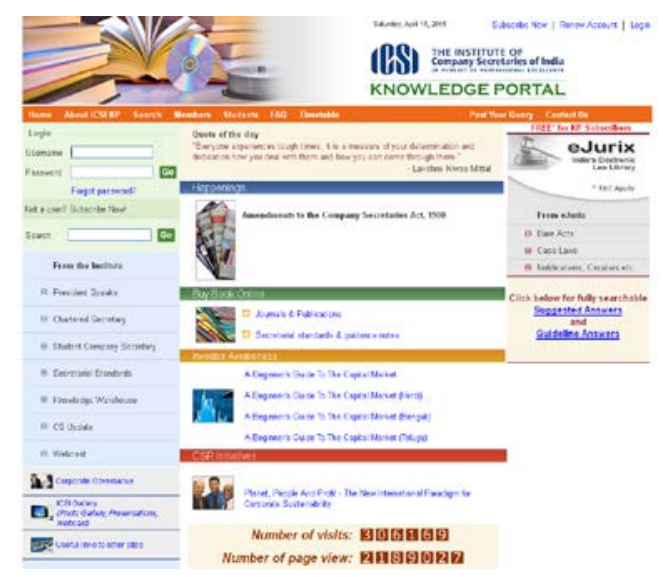

Fig. 3. ICSI - Knowledge Portal

Another example of knowledge portal is depicted in Fig. 4 (available at [20]). The goal of its solution is to convince to company products as well as to offer complete courses devoted to accelerate user skills.

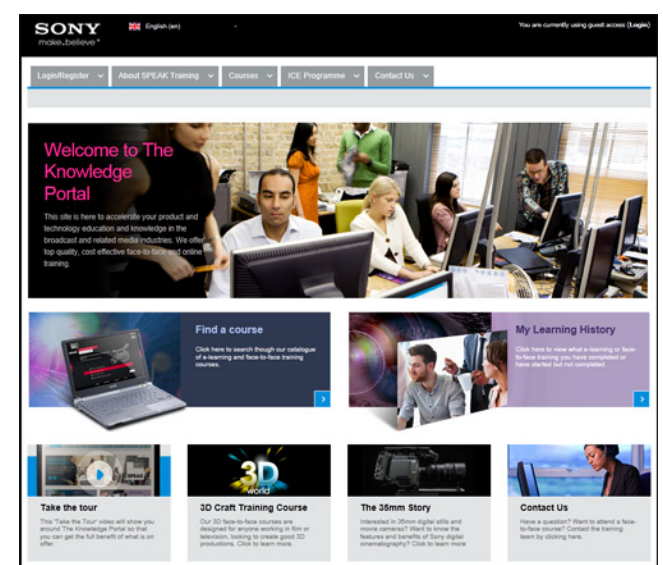

Fig. 4. Working with SONY Knowledge Portal 
A useful tool for strengthening a network of people who are excluded can be a portal of knowledge. It serves not only as a tool to convey information, but above all to enrich and exchange their knowledge resources. Knowledge portal provides access to knowledge resources that are owned by all of the entities forming the network issues of excluded people. The first impulse to gain specific knowledge resources is to determine user's needs. Information goes to the portal, which locates the appropriate resource, a category of knowledge transfer process. Then the knowledge portal allows supplement domain knowledge. In this way, the knowledge portal becomes a compendium of knowledge on the particular matter. Site work requires not only knowledge of information technology, but appropriate organizational structure and knowledge management strategy. The proper functioning of the portal of knowledge brokers play an important role. They should be in the portals of knowledge as individuals or institutions performing oversight knowledge development in the portal. The main task of the broker is:

- assessment of the needs of the knowledge,

- location of resources,

- supervision of the transfer,

- assessment of the degree of absorption and utilization of knowledge.

All operators should be interested in the proper functioning of the portal of knowledge. Knowledge that remains in the resources of the organization is the basis for the acquisition of new resources. We have in this case to deal with a spiral of knowledge that all time develops, through which actors are able to develop. Basic knowledge resources of the company are based on five categories of knowledge (compare [18]):

- codified knowledge,

- explicit knowledge,

- knowledge protected,

- tacit knowledge,

- latent knowledge.

The portal should provide exploration of tacit knowledge and latent one. These two categories can contribute significantly to the development of the organization, and thus to achieve a competitive advantage. Portals should not only be source for the implementation of business functions typically associated with competitiveness, achieving measurable financial results. They should also be used for indirect actions that will achieve the objectives of a typical business. Different types of social organizations also need such solutions. A multitude of knowledge, which allows to solve problems of social institutions requires it to organize and codify the first stage of creating the portal. The next step is to complete this knowledge different solutions at the local level. The establishment and operation of such a portal will allow institutions to function more efficiently to deal with the problems of excluded people. Perhaps those who are excluded will return to society. However, their efficiency and effectiveness will be determined only by time. 


\section{A GENERAL CONCEPT OF KNOWLEDGE PORTAL FOR EXCLUSIVES}

Highly specialised knowledge portal will be presented through description of two portal elements: assumptions and functionality. In the last part KP architecture will be demonstrated in graphical form.

\section{Functionality}

Designing the fundamental functionality of the portal for exclusives we have to take into consideration dimensions of the exclusion mentioned above. The used cases should be aggregated into following groups:

- $\quad$ support for enter / return to the labour market,

- goods and services flow targeted to exclusives,

- communication and content management features.

The features focused on the help for the unemployed have to fulfil the following goals:

- Gather and present job offers that may be beneficial but also accessible by exclusives. There will be possibility for entering such offers directly into portal but also the portal will be loaded automatically with suitable offers from other portals specialized in job offering.

- Gather and present profiles of people looking for a job.

- Automatically match the employers and employees and suggest corresponding job offers for candidates and candidate's profiles for employers.

- $\quad$ Encourage exclusives to register their profiles and to make an effort to find or change a job.

- $\quad$ Enhance skills and competencies of candidates by e-learning features.

- Encourage employers to give a chance to exclusives by showing them benefits of hiring exclusives.

The next group of portal's features will have the following goals:

- Collect offers of goods or services directed to exclusives that are available by no charge or by a very low prize. Such offers will be entered directly to portal but also will be searched in other trade portals.

- Present the announcements of exclusives specifying the goods or services that they require.

- Match the necessitous with the offers.

In both those groups of functionalities we have to remember that the exclusives may use the portal directly or be represented by the people engaged in the process of help for exclusives such as social workers. We also take into account that the personal data of exclusives must be protected with special care.

The last mentioned part of functionalities deals with the educational and communicational features directed to:

- Politicians, journalists, researches and others that deal with the problem of exclusives and want to learn about problems or exchange ideas.

- $\quad$ Exclusives - to be aware of the law or the programs dedicated to help them.

\section{Assumptions}


We assume the following groups of users are the target users of proposed portal:

- Policy makers - represented by politicians and officials who are responsible for legal solutions, law creation and adjustments.

- Social workers employed in:

o Governmental / local governmental units.

o NGO's - Non-governmental organizations.

- Institutions interested or engaged in the exclusion problem like universities/ scientific organisations and their researchers, media and journalists.

- Independent entities which are interested in the exclusion problem.

- Commercial enterprises which develop programs / solutions targeted to help excluded groups.

By using another perspective we can divide the users into:

- Corporate users representing authority organisations.

- Individuals representing basically themselves that consist of:

o Authorities that should be verified.

o Regular users.

The main basis of the portal assume that every published content is available for all portal users (except from the personal data of exclusives). There will be no confidential matters stored in the portal so there is no need to build sophisticated information protection module.

No confidentiality assumption determines the simplicity of permissions model in the portal. The administrators of the portal will be able to configure it's modules and manage the permissions for every defined role, but there is no need to limit the access to the specific content.

We perceive that if we build a dedicated authentication module with separated credential management it will become a serious pain point for the users who will be forced to create and remember yet another user login and password. That is why we would like to integrate with as many as possible authentication providers that can exchange the data with the portal. Such approach will allow the users to use in our portal the same credentials as they are using in their enterprise systems or social solutions. Our portal will be integrated with:

- LDAP solutions,

- Facebook/ twitter / google accounts.

Our authorisation module architecture approach will allow organisational users to authenticate in our portal with the corporate login and password or even include the portal into the corporate SSO (single sign-on) solution. Individual users will be able to access the portal with the private facebook account and sign in automatically.

Of course we can use the mixed mode of authentication which means that corporate users can use also their private social accounts if they prefer or if the integration with the corporate LDAP will be impossible.

The corporate users of the portal should be verified by:

- Portal administrators,

- Organisation representatives. 
In case of the individual users that should be verified - this task will be done by portal administrators.

One of the most important assumptions regards the functional offerings of the portal. It is not designed to work with specific excluded people and solve their particular problems. The main aim of the portal is to connect, enhance the interchange of ideas, knowledge and experience between the experts engaged in exclusion problem. It is designated to inspire all the stakeholders to solve the general problem of exclusion and provide them with relevant information and knowledge. That is why the portal will not consist workflow functionality/ application processing capabilities but it is focused on information and knowledge tools processing, ideas management, communication platform and e-learning modules.

\section{Architecture}

We propose the Knowledge Portal for Exclusives (KPE) to be built in traditional 4 layers architecture:

- Integration layer - build to provide communication with the other systems collaborating with our portal. They can be:

o Authentication provider like google, facebook, twitter, MS and others

o Content delivery portals belonging to governmental organisations or similar initiatives focused on exclusion problem

o Commercial/ business portals publishing jobs offers and portals providing consumer to consumer \& business to consumer sales services.

- Database layer - build as relational database storing the business and process objects. In this layer we will store also all documents, multimedia files, learning objects that has no relational structure. This layer will also provide the services of reporting and integration with other systems.

Database layer will be supported also with Knowledge Base. The knowledge to the Knowledge Base will be supplied by:

o Experts (portal users)

o Knowledge exploration module that will be operated by portal power users with data exploration skills.

- Application layer that will be responsible for whole business logic. It will provide:

o the basic portal functionality,

o the communication services that will give the users possibility for on-line bilateral communication, teleconference services, off-line communication,

o e-learning services with all capabilities for hosting and providing on-line courses, 


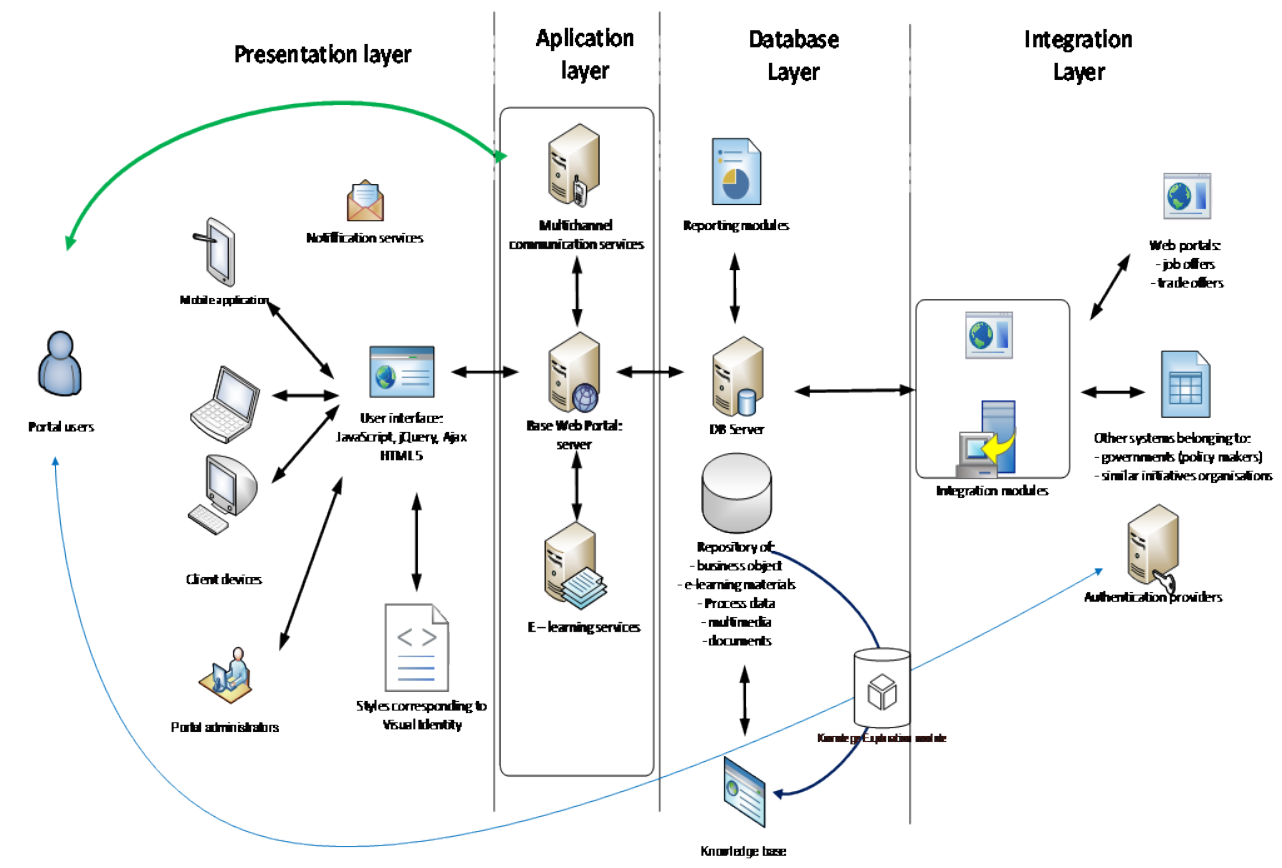

Fig. 5. Architecture of Knowledge Portal for Exclusives

- $\quad$ Presentation layer build in portal technologies (which means that all the portal features will be accessible by web browser). We must take into account that for some users the portal will not be a tool in which they will work every day. That is why from user perspective it is crucial to provide them notifications of all important event happening in portal as new available content, tasks for users, activities expected to be done by users and others. Such notifications will be provided by:

o Automatically generated emails,

o Mobile application push notifications,

o Newsfeed published by social portal as Twitter or Facebook.

Presentation layer will provide end users access to the information and knowledge stored in the database layer with regard to: users permissions and users preferences (content should be targeted to end user's needs and requirements).

\section{IMPLEMENTATION EXAMPLES OF KNOWLEDGE PORTALS FOR EXCLUSIVES IN LOCAL GOVERNMENTS}

Presented earlier general knowledge portal for exclusives can be implemented at all levels of the modern society. We focus on regional implementation of KPE in Silesia agglomeration. There are some "sectors" on existing portals devoted to exclusion problems (see Fig. 6). 


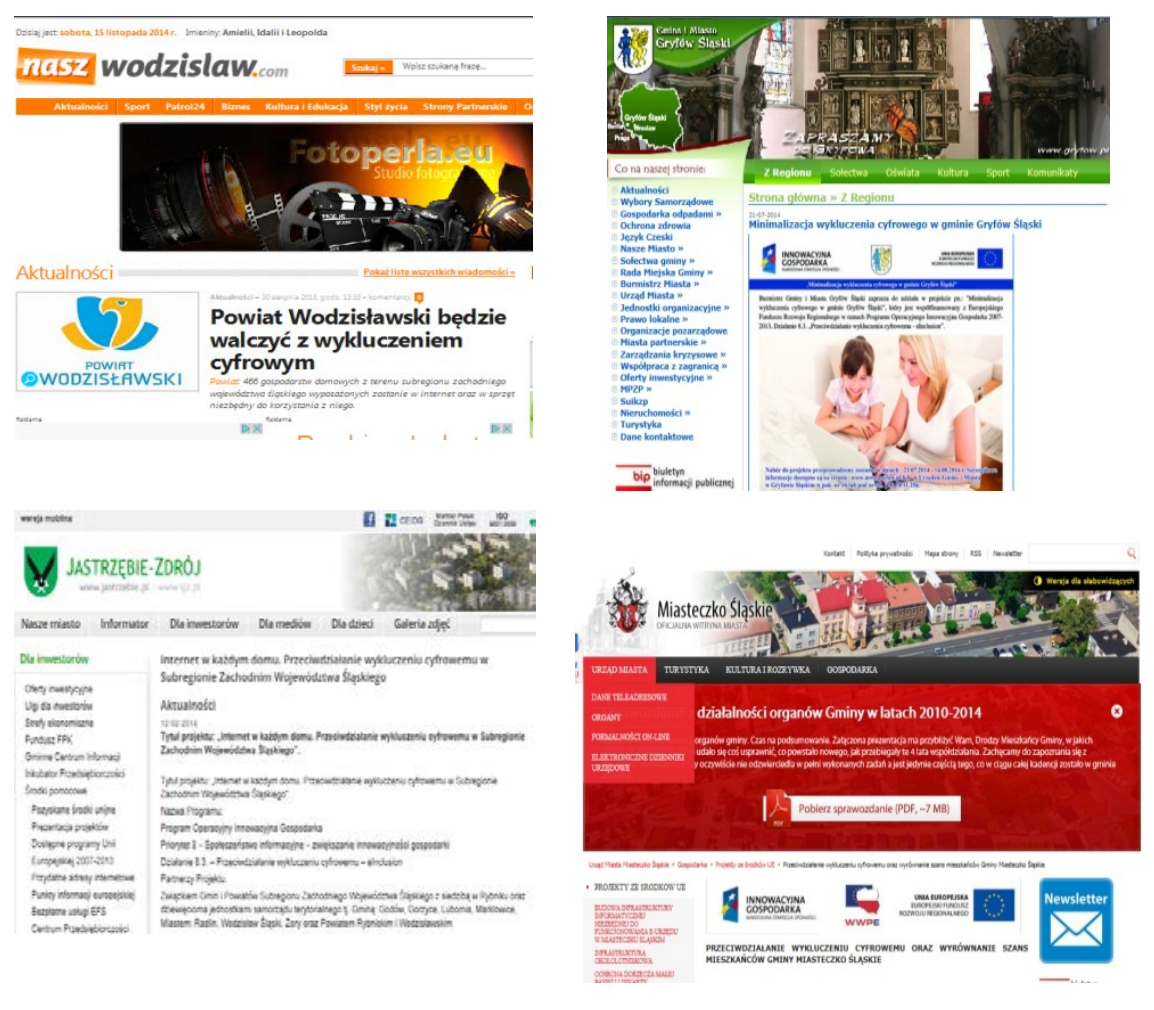

Fig. 6. Portals of Silesia agglomeration with exclusive quests

The problem of supporting exclusives is very important in Silesia region. During transformation starting at the beginning of 90's in Poland many miners and workers of heavy industry lost their jobs. So the problem became very important also for local governments. The content of the selected Silesian cities portals: Jastrzebie Zdroj, Wodzislaw Slaski, Gryfow Slaski oraz Miasteczko Slaskie reflects the typical approach to "excluded" people; actually on these portals habitants may find basic information about exclusive phenomena presenting some initiatives and projects. Therefore the idea of development KPE seems to be very natural.

The presentation of general assumptions and specialty such of portals we start from itemizing of potential users. At least the following group should be included:

- Knowledge bidders - e.g. institutions responsible for the creation of legal solutions, laws and regulations, NGOs, institutions interested or involved in the problem of exclusion (universities, research institutions, scientists, the media, journalists), independent entities interested in the problem of exclusion.

- Individual users, - e.g. citizens of that region who are currently subject to marginalization or exclusion, and those seeking to achieve social equality.

- Social workers, commercial enterprises that develop software solutions 
targeted to excluded groups and individual experts.

- Experts, associated with the preparation of educational materials and the development of e-learning courses for end users platform.

Defining technological assumptions and considering general contexts we expect from the discussed platform:

- Full integration, assuming that in the basic system infrastructure - service target group (in this case those who are vulnerable or excluded) relies on integration of heterogeneous information generated by specific entities within eg. A single portal and using the presentation layer respectively made available to specific groups of customers.

- Groupware approach which is based on intelligent infrastructure, critical systems and cooperating users, helping to improve efficiency in the pursuit of counteracting exclusion or marginalization.

- Applying of the comprehensive contact covering implementation of smart technology management and public information resources, allowing to systematize and increase citizens' access to information and knowledge, concerning measures to counteract exclusion and marginalization phenomena using ICT infrastructure.

As a result we may expect the following benefits of KPE at the local level:

- increasing the number and quality of habitants's contacts with the public,

- building a communication network between the public sector and people,

- reducing the sense of isolation and loneliness among the excluded,

- integration of existing information systems,

- adaptation of persons excluded or marginalized to benefit from services that enable increase their mobility and social integration of access to ICT solutions, health care in order to develop greater independence and autonomy from third parties,

- reducing social exclusion phenomena.

\section{CONCLUSIONS AND FURTHER RESEARCH}

One of the most important problems of the modern society at the local, national and global levels is exclusion processes. The next findings can be formulated from the research:

- phenomena exclusion and inclusion in society are complex and multidimensional. Therefore investigation of such processes is difficult also because of differentiation of components, approaches and dimensions,

- information and communication technologies must support all processes belonging to registration and all services typical for exclusion and inclusion phenomena in modern society,

- the best solution for the discussed problems is specialized knowledge portal proposed in the paper as a form of an initial version. At the beginning architecture will be developed for some narrow application and systematically extended covering new areas and levels of supporting.

Further investigations can be devoted to more deeply analysis of the problem in order to fulfill requirements of knowledge portal users. For example specification 
of knowledge bases and courses essential at local and/national level of administration.

\section{REFERENCES}

[1] Silver, H., 1994, "Social Exclusion and Social Solidarity: Three Paradigms", International Labour Review, Volume 133, Numbers 5-6, pp. 531-578.

[2] Saith, R., 2007, Social Exclusion: The Concept and Application to Developing Countries [in:] Stewart, F., Saith, R. and Harriss-White, B., (eds.), Defining Poverty in the Developing World, Palgrave, pp. 75-90.

[3] Sen, A., 2000, Social Exclusion: Concept, Application, and Scrutiny, Asian Development Bank.

[4] De Haan, A., 1999, Social Exclusion: Towards an Holistic Understanding of Deprivation, Department for International Development, London.

[5] Burchardt T., Le Grand J., and Piachaud D., 2002, Introduction, [in:] Hills, J., Le Grand, J. and Piachaud, D., Understanding Social Exclusion, Oxford University Press, Oxford.

[6] Bhalla, A. and Lapeyre, F., 1997, "Social Exclusion: Towards an Analytical and Operational Framework", Development and Change, Volume 28, pp. 413-433.

[7] Fischer, A., 2011, Reconceiving Social Exclusion, BWPI Working Paper 146, Brooks World Poverty Institute, Manchester.

[8] Barry, B., 1998, Social Exclusion, Social Isolation and Distribution of Income, Centre for Analysis of Social Exclusion, London School of Economics, London.

[9] Hickey, S. and du Toit, A., 2007, Adverse Incorporation, Social Exclusion and Chronic Poverty, Working Paper 81, Chronic Poverty Research Centre, University of Manchester.

[10] Warschauer M., 2004, Technology and Social Inclusion. Rethinking the Digital Divide. The MIT Press, Massachusetts Institute of Technology.

[11] Rawal N., 2008, ”Social Inclusion and Exclusion: A Review”, Dhaulagiri Journal of Sociology and Anthropology Vol.2. pp. 161-180.

[12] Social Exclusion portal: http://www.gsdrc.org/go/topic-guides/social-exclusion/definitions-anddifferent-understandings-of-social-exclusion [2014-04-23].

[13] Exclusion-Inclusion in Suburb: - http://www.hioa.no/eng/About-HiOA/Centre-for-Welfare-andLabour-Research/NOVA/NOVA-Projects/Prosjekter-migrasjon-og-transnasjonalitet/Avsluttedeprosjekter/2011/Exclusion-and-inclusion-in-the-suburb/(language)/eng-GB [2015-04-23]

[14] H2020 sections: http://ec.europa.eu/programmes/horizon2020/en/h2020-sections [2015-04-23]

[15] World Bank website: http://www.worldbank.org/en/topic/socialdevelopment/brief/socialinclusion [2015-04-23]

[16] Collins Dictionary website: http://www.collinsdictionary.com/dictionary/english/social-inclusion [2015-04-23]

[17] Internet portal - http://en.wikipedia.org/wiki/Internet_portal [2015-04-23].

[18] Knowledge concept - http://en.wikipedia.org/wiki/Knowledge [2015-04-23].

[19] RTI Knowledge Portal - http://rti.img.kerala.gov.in/RTI/index.jsp [2015-04-23].

[20] Sony Knowledge Portal - https://training.sony-europe.com/ [2015-04-23]. 